DIE ROLLE VON AUTOBAHNEN ALS RAUMORDNUNGSPOLITISCHE MASSNAHME FUR DEN PERIPHEREN RAUM

Claudia Radenz *

IZVLEČEK

UDK $911.3: 711.2: 625 \cdot 711 \cdot 3(430,1)=30$

\title{
VLOGA AVTOCESTNE MREŽE V PROSTORSKIH NACRTIH OBROBNIH OBMOČIJ
}

Izgradnja infrastrukture $\mathbf{v}$ obrobnih območjih je $\mathbf{v}$ veliki meri usmerjena v izgradnjo avtocest. Avtor predvsem prikazuje negativne posledice, med katerimi prednjači depopulacija.

ABSTRACT

UDC $911.3: 711,2: 625 \cdot 711.3(430.1)=30$

THE IMPACT OF HIGHWAYNETS IN REGIONAL PLANS OF PERIPHERAL AREAS

Regional infrastructure of peripheral zones bases on a proper sistem of highways: The autor discusses mostly negativ impacts of transregional highways and among them specialy depopulation.

1. Problemstellung

Die raumstrukturelle Entwicklung in der Bundesrepublik Deutschland ist, wie in anderen hochentwickelten Industrieländern auch, durch regionale Disparitäten geprăgt. Eine Voraussetzung für den Abbau dieser wirtschafts - und gesellschaftspolitisch unerwlinschten Disparitäten ist nach ubbereinstimmender Ansicht von Theorie und Praxis die gezielte Verbesserung der Standortbedingungen in den strukturschwachen Räumen, d. h. die Aufhebung regionaler Standortnachteile. In diesem Zusammenhang wird in den Fördermassnahmen, wie etwa regionale Wirtschaftsförderung, Zonenrandförderung usw., dem Instrument der Infrastrukturinvestition ein hoher Stellenwert beigemessen. Eine besondere Impulsfunktion für das regionale Wirtschaftswachstum erwartet man dabei von Investitionen in der Verkehrinfrastruktur, insbesondere von der Anbindung schwach strukturierter Raume an das interregionale Fernstrassennetz.

* Dipl. geogr., Lehrstuhl für Wirtschaftsgeographie und Regionalplanung, Universităt Bayreuth, Universitătsstrasse 31 
2. Autobahnplanung im Wandel der Planungsphilosophien und der gesellschaftlichen Werte

Diese Erwartungen uber die Funktion des Fernstrassenbaus spiegeln dabei sehr gut den Wandel der Planungsphilosophien wider. In den 50-er Jahren stand zunächst das Ziel, Verbindungen zwischen den wirtschaftlichen Zentren zu schaffen, im Vordergrund. Diese Agglomerationsorientierung, die nicht nur in der Verkehrsplanung, sondern in nahezu sämtlichen Politikbereichen bis heute vorherrschend ist, förderte auch durch den Ausbau der Verkehrsinfrastruktur die Verdichtungsräume immer mehr, wăhrend die peripheren Räume benachteiligt wurden. Seit Mitte der 60-er Jahre, als wegen der damals günstigeren Lohn-/Gehaltssituation und der Erweiterungsmöglichkeiten eine erhebliche Anzahl von Industriebetrieben ganz oder teilweise in den peripheren Raum verlagert wurde, kam es verstärkt zum Bau bzw. der Planung von Autobahnen zwischen diesen Gebieten und den Verdichtungsräumen. Seit dieser Zeit gewannen raumordnerische bzw. regionalpolitische Kriterien an Bedeutung (Gleichwertigkeit der Lebensbedingungen, gleichwertige Kommunikations- und Mobilitätschancen usw.) und der rein verkehrswirtschaftliche Aspekt (Bedarfsdeckungsprinzip) trat bei der Argumentation für einen Autobahnbau in peripheren Räumen zumindest teilweise zurück.

Wahrend der Zeit des Wirtschaftswachstums bestanden bei der Planung und Durchfürung von Autobahninvestitionen keinerlei Zweifel an der wachstums - und strukturverbessernden Wirkung ( $z$. B. neue Arbeitsplätze) dieses regionalpolitischen Instruments. Die Bedeutung des Strassenbaus fur das gesamtwirtschaftliche und das regionale Wachstum wurde aus der Vermutung abgeleitet, dass von neuen oder wesentlich verbesserten Strassenverbindungen dauerhafte Entwicklungsimpulse ausgehen würden.

Seit einiger Zeit mehren sich infolge finanzieller Restriktionen, verănderter Energiesituation (Olkrise), stärkerem Bewusstwerden der verschlechterten Umweltbedingungen und insgesamt eines Wertewandels in der Gesellschaft (Umweltbewusstsein, stärkere Mitbestimmungsforderungen, Regionalismusbestrebungen, kleinräumigere Vorstellungen usw.) die kritischen Stimmen gegen Massnahmen im Bereich der Grossinfrastruktur und fuhren damit auch zu einer Sensiblisierung der Bevölkerung beim Bau bzw. der Planung von Autobahnen. Die Kritik wird dabei nicht nur von ökologischer Seite geăussert, die sich gegen den hohen Flächenverbrauch, die Lärm- und Abgasbelastungen, die hohe Streusalzintensităt im Winter sowie gegen Schädigungen der Tierund Pflanzenwelt wendet. Neben diesen Argumenten spielen auch an- 
gesichts der ungünstigen wirtschaftlichen Situation die enormen finanziellen Aufwendungen für eine Autobahn (durchschnittlich ca. $8 \mathrm{Mio}$. DM pro $\mathrm{km}$ ) eine Rolle. Auch kritische Ausserungen von Wissenschaftlern uber die Raumwirksamkeit von Autobahnen tragen dazu bei, dass die Eröffnung eines neuen Autobahnabschnittes nicht mehr uneingeschränkt als politischer Erfolg verbucht werden kann. So werden zunehmend die arbeitsplatzschaffenden Effekte beim Bau und während der Betriebsphase einer Autobahn angezweifelt sowie die Hoffnungen auf Neuansiedlung von Industriebetrieben, die insgesamt gerade in peripheren Regionen nur noch sehr selten vorkommt.

3. Die Bedeutung von Fernstrassen für die regionale Wirtschaft und die Bevölkerung

Trotz der verstărkten Kritik seit Mitte der 70-er Jahre erhofft sich immer noch ein Grossteil der Politiker eine Lösung der Probleme. des peripheren Raumes durch grossinfrastrukturelle Massnahmen wie den Autobahnbau. Diese Hoffnung beruht auf den in der Vergangenheit - unter völlig anderen Rahmenbedingungen - vermuteten und damals auch teilweise festgestellten positiven ökonomischen Wirkungen einer Fernstrasse (wie Neuansiedlung von Betrieben, Verbesserung der Erreichbarkeit und des Images von Fremdenverkehrsgebieten, Schaffung neuer Arbeitsplätze, Ausdehnung des Absatzgebietes, Senkung der Transportkosten usw.).

Meiner Meinung nach werden bei der Argumentation zu wenig die Wirkungen auf die regionsansässige Bevölkerung, d. h. soziale Aspekte, berücksichtigt. Sicher kann man auch die These aufstellen, dass der Bau einer Autobahn im wesentlichen Vorteile für die Bevölkerung bringt, wie etwa kürzere Pendlerwege und bessere Erreichbarkeit von Versorgungs- und Freizeiteinrichtungen ausserhalb der Region. Die wenigen Untersuchungen über diese sozialen und psychologischen Wirkungen weisen jedoch eher auf negative Aspekte hin. So ist das durch einen Autobahnbau oft erst ermöglichte bzw. erleichterte Pendeln hăufig nur eine Vorstufe für einen späteren Wohnortwechsel in einem Verdichtungsraum, die den Bevölkerungsverlust der peripheren Räume noch verstărkt.

Auch der zunăchst als positiv zu beurteilenden Verbesserung der Erreichbarkeit von Einkaufsmöglichkeiten (mit einem grösseren Angebot und günstigeren Preisen) steht der Verlust von Kaufkraft in der peripheren Region gegenüber. Verstärkt wird dieser Effekt noch durch die Ansiedlung von grossen Einkaufszentren an verkehrsgünstigen Standorten, wodurch unter Umständen die Geschäfte im 1ăndlichen 
Raum verdrängt werden, was sich dann wiederum negativ auf den nicht . motorisierten Teil der Bevölkerung (wie Hausfrauen, ältere Leute) auswirkt. Weiterhin hat der Bau einer Autobahn auch Auswirkungen auf die Wohnortqualităt und die Siedlungsstruktur. Neben der Lufiverunreinigung und der Lărmbelăstigung durch die Kraftfahrzeuge kann der Bau auch zu einer Zerschneidung von Siedlungseinheiten fuhren, was den Informationsaustausch und die sozialen Kontakte erschwert.

Nicht unerwähnt bleiben soll andererseits, dass es in einem Bereich ganz eindeutig nur positive Effekte einer Autobahn sowohl für die Bevölkerung als auch für die gesamte Volkswirtschaft gibt, den Aspekt der Verkehrssicherheit. Es lässt sich statistisch nachweisen, dass Autobahnen wegen ihrer verkehrs- und bautechnischen Gestaltung (getrennte Fahrtrichtungen, Standstreifen, kreuzungsfrei usw.) einen erheblichen Beitrag zur Verringerung der Unfallhäufigkeit leisten.

So liegt in der Bundesrepublik der Anteil der Unfalle auf Autobahnen an den gesamten Strassenverkehrsunfällen (mit Personenschaden) nur bei $4 \%$, obwohl hier etwa ein Viertel aller Fahrleistungen (KFZ $/ \mathrm{km}$ ) erbracht wird. Dies soll jedoch nicht heissen, dass man mit diesem Argument der verbesserten Verkehrssicherheit jeglichen Autobahnbau auch in peripheren und damit in der Regel verkehrsschwachen Gebieten rechtfertigen kann, da hăufig der Ausbau von bestehenden Strassen oder Ortsumgehungen einen ähnlich positiven Effekt bezüglich der Verkehrssicherheit erzielen, jedoch ohne den enormen finanziellen Aufwand und die einschneidenden negativen Wirkungen auf Natur und Landschaft.

Die Betonung der sozialen Auswirkungen einer Autobahn erscheint nicht zuletzt im Sinne einer regionalen Regionalpolitik sehr wichtig, könnte dadurch die Kommunikation der verschiedenen und bislang nicht miteinander verbundenen, ja hăufig sich sogar bekämpfenden Personengruppen im peripheren Raum erheblich verbessert werden.

Abschliessend möchte ich erwähnen, dass trotz der Kritik an dieser regionalpolitischen Massnahme und dem Aufzeigen vorwiegend negativer Effekte durchaus nicht jede Autobahnplanung bzw. - bau abgelehnt werden soll, da es trotz des heute im gesamten Bundesgebiet erreichten relativ guten Ausbauzustandes der Bundesfernstrassen noch eine Reihe von Gebieten gibt, die bisher nur unzureichend an das überregionale Fernstrassennetz angeschlossen sind. Dies sind keineswegs nur rein agrarisch geprăgte Regionen, sondern - wie etwa Oberfranken - auch hochindustrialisierte Gebiete mit vielfältigen uberregionalen bzw. internationalen Kontakten, die jedoch aufgrund der mangelhaften Verkehrserschliessung erheblich beeintrăchtigt werden. Zwar ist das Verkehrsaufkommen hier vergleichsweise gering, doch spielt dabei auch die Frage 
eine Rolle, inwieweit durch derartige staatliche Massnahmen ein Beitrag zu einer Stărkung des Regionalbewusstseins der Bevölkerung geleistet werden kann.

\section{VIJOGA AVTOCESTNE MREŽE V PROSTORSKIH NAČTIH OBROBNIH} OBMOČIJ

Med posameznimi območji ZR Nemčije so občutne razlike $\mathbf{v}$ doseženi stopnji družbenoekonomskega razvoja. Zaradi tega se $\mathbf{v}$ posameznih manj razvitih območjih uveljavljajo različne regionalne subvencije, ki se pogosto uporabljajo za vzpodbuditev infrastrukturnih naložb. Posebno veliko si periferna območja obetajo od investicij $v$ prometno infrastrukturo, posebno tako, ki bi slabše razvita območja povezala $\mathrm{z}$ medregionalnim cestnim omrežjem.

Medtem, ko glede izgradnje avtocestnega omrežja v casu gospodarske prosperitete ni bilo dilem, so $v$ zadnjem casu vedno bolj glasne pripombe na račun filozofije avtocestne izgradnje. Avtor članka se zoperstavlja neutemeljeni in iz aspekta višje razvitih regij nacrtovani izgradnji avtocest, ki bi vodile čez periferna območja. Tezo utemeljuje s številnimi dokazi.

Res se da dokazati, da avtoceste zboljšujejo kvaliteto življenja s tem, da skrajšujejo pota na delo oziroma rekreacijska območja in trgovsko infrastrukturo približujejo vsemu prebivalstvu. Vendar se je v preteklosti pokazalo, da je delovna migracija neredko korak h kasnejši preselitvi. Ker se $z$ naselitvijo veletrgovin na pomembnih križiščih zmanjšuje pomen lokalnih trgovin, te propadajo, hkrati odmira prebivalstvo in lokalna trgovska infrastruktura. Omeniti pa je treba, da pripomorejo avtoceste $\mathrm{k}$ občutnejšemu izboljšanju prometne varnosti. Vendar se da prometno varnost $\mathrm{v}$ perifernih območjih izboljšati tudi $\mathrm{z}$ manj dragimi, predvsem pa ekološko manj vprašljivimi projekti (mestne obvoznice, hitre ceste ...)

Doslej so avtoceste gradili prvenstveno $\mathrm{z}$ namenom povezati osrednja industrijska, upravna in urbana območja. Prihodnost pa zahteva planiranje tudi takih avtocest, ki agrarnih in perifernih regij ne bodo le prečkale, temveč aktivno vključile. 
- Karte 1 Netz der Bundesautobahnen 1983

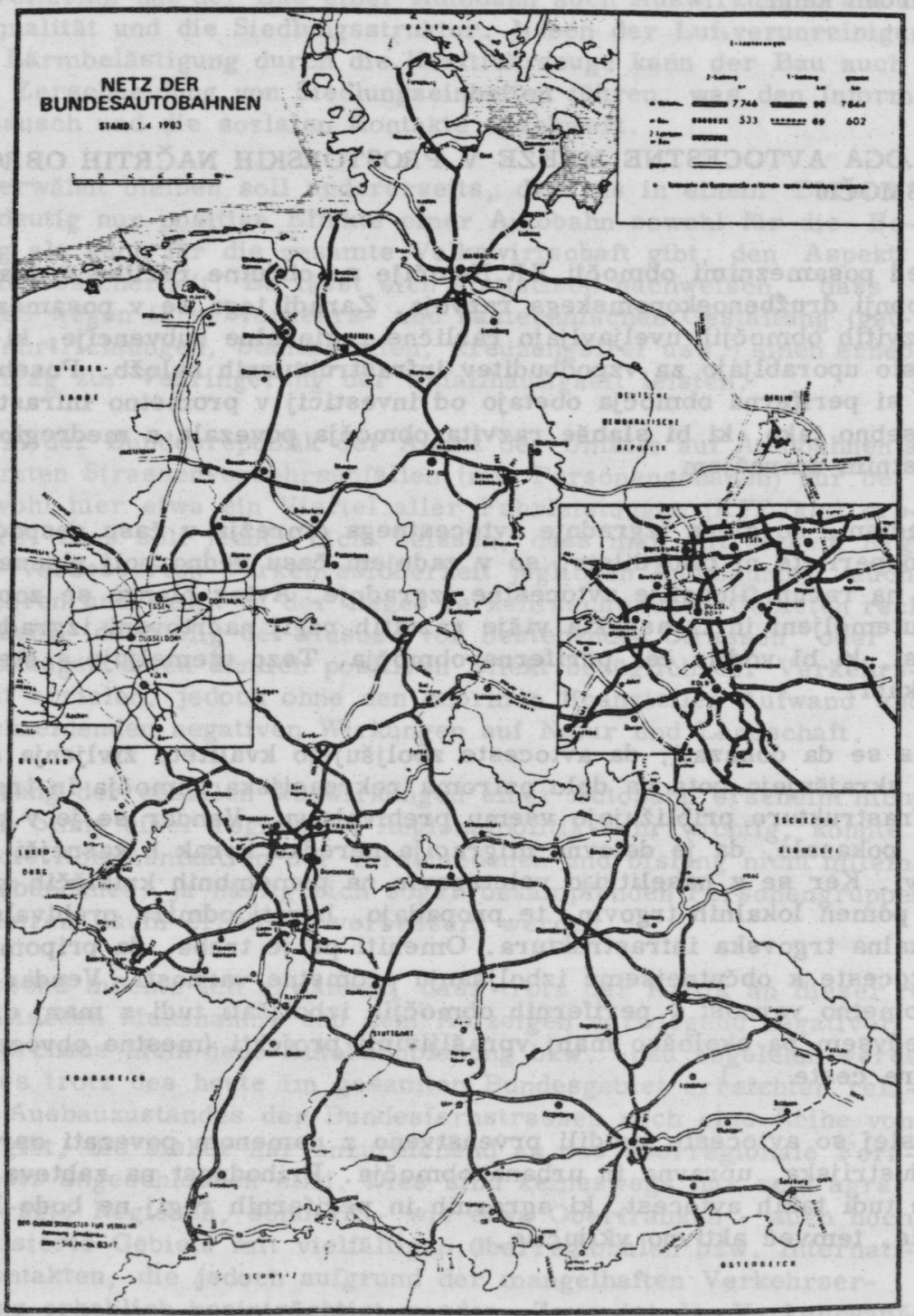

